\title{
Effect of Textual Errors on The Evaluation of a Foreign Online Store
}

\author{
Vanessa Bracamonte Lesma ${ }^{1, *}$, Hitoshi Okada ${ }^{2}$ \\ ${ }^{1}$ SOKENDAI (The Graduate University for Advanced Studies), Japan \\ ${ }^{2}$ National Institute of Informatics, Japan \\ ${ }^{1}$ vbracamonte@nii.ac.jp*; ${ }^{2}$ okada@nii.ac.jp; \\ * corresponding author
}

\begin{abstract}
We conducted an experimental study among Japanese consumers to investigate the impact of textual errors on the perception and evaluation of an online store in a cross-border context. In particular, we proposed that the presence of textual errors would result in lower perceived ease of use, ease of communication and trust in a foreign online store. The experiment considered two types of errors, related to the use of language and to the completeness of translation. Four experimental conditions with different levels of textual errors were evaluated. We conducted a survey in Japan, obtaining a total of 1919 responses which were analyzed using structural equation modeling. The results showed that the presence of textual errors had a negative effect on all factors in the proposed model, compared to the absence of such errors. We discuss these results and their implications for foreign online vendors.
\end{abstract}

Keywords: Cross-border electronic commerce; Consumer behavior; Trust; Ease of use; Ease of communication;

\section{Introduction}

The design of an online store provides cues to the consumer, influencing their evaluation on different dimensions. Previous research has considered design elements, such as images [5] or colors [4] for example, and how they can have a positive influence on the perception of an online store. On the other hand, flaws or errors in the design can negatively affect this perception [7]. One type of error that has been considered are errors in the quality of the textual content of the website [7]. However, this characteristic has been studied in a domestic context, where the consumer and vendor usually share the same language. In this study, we consider the influence of textual errors in a cross-border electronic commerce context where, in addition to errors or flaws in the language, translation issues may also be relevant. In cross-border electronic commerce is the possibility that the vendor and the consumer have different languages, but few studies have considered the negative impact that a partial translation or language errors in a foreign online store may have on its evaluation.

The aim of this study is to validate the negative effects that textual errors can have on the perception of the foreign online store. We hypothesize that the presence of textual errors will have a negative impact on quality components of the website such as ease of use and ease of communication and on trust. Trust is an important factor in the acceptance of foreign online stores, as uncertainty in the consumer is one of the main reason for not trying cross-border electronic commerce [3]. With this study, we hope to contribute to the understanding of issues that may affect trust and other dimensions of perception of a foreign online store.

\section{Theoretical Framework}

We define ease of communication as the degree to which a user perceives that it would be easy to contact and communicate with the vendor. Being able to communicate with the online store is important for the consumer [17] in order to have access to further information or in the case of any problems. Perceived ease of use is defined as "the degree to which a person believes that using a particular system would be free of effort." [6]. Ease of use is one of the two factors proposed to by Davis [6] as part of a technology acceptance model (TAM) for user behavior, and it is considered an important factor for the acceptance of websites [14]. 
Both ease of use and communication factors are components of quality in online stores [1] [12] [17]. The perception of quality in the website can be affected by flaws in the design [7], and so textual errors may have a negative impact on these factors.

H1: Textual errors result in lower perceived ease of communication with the foreign online store

$\mathrm{H} 2$ : Textual errors result in lower perceived ease of use of the foreign online store

Trust is defined as a belief or confidence in the online store [5], that it will act favorably towards the consumer [9]. Design characteristics are among the different determinants of trust [22], and design manipulation can have positive, or negative, effect on the perception of trustworthiness of a website [13]. Therefore, flaws in the design such as textual errors may negatively affect trust in the online store.

H3: Textual errors result in lower trust in the foreign online store

The lack of direct interaction with the online vendor that is the characteristic of electronic commerce is one of the reasons for uncertainty in the consumer [9] [16]. Improving perception of ease of communication may increase the perception of trustworthiness of the online store.

H4: Higher perceived ease of communication will result in higher trust in the foreign online store

Though previous studies have considered ease of use and communication related factors as different dimensions of quality in the website [12] [17], the relationship between them has been less studied. Nevertheless, being able to obtain the resources in order to be able to use a system, that is, having a perception of internal or external control, has been identified as a determinant of ease of use [21]. The perception of being able to communicate with the vendor may act as a facilitating condition to gain knowledge or control of the system, and therefore would have a positive effect on ease of use. In turn, perceived ease of use has been found to affect trust in the website [8].

H5: Higher perceived ease of communication will result in higher perceived ease of use of the foreign online store

H6: Higher perceived ease of use will result in higher trust in the foreign online store

The research model with all hypotheses is presented in Figure 1.

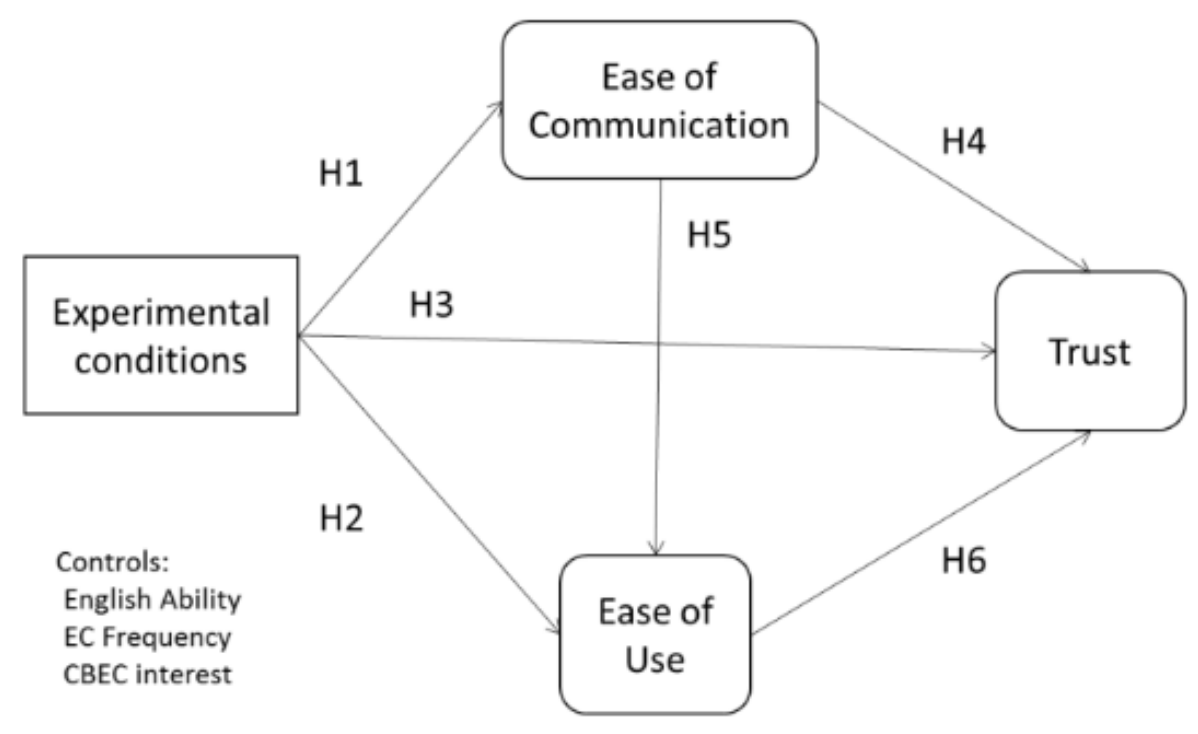

Figure. 1. Proposed model

\section{Method}

\subsection{Participants}

We conducted an online survey among Japanese consumers. An invitation to answer a preliminary questionnaire was sent through a survey company. The preliminary questionnaire included questions about demographic information 
and online shopping frequency. The people who responded to the invitation and answered the preliminary questionnaire were selected to take the main questionnaire.

\subsection{Experimental design}

In order to examine how different type of errors influence the perception of a foreign online store, we considered two types of errors, with two levels each. The types of error were defined by errors in the use of Japanese language and the completeness of the translation in the website. For the error in the use of Japanese language, the levels were correct language and incorrect language. For the completeness of translation the levels were all Japanese language (full translation) and a mix of Japanese and English language in the website (partial translation).

The types and levels in four combinations: (1) correct language and full translation (Correct-Full), (2) correct language and partial translation (Correct-Partial), (3) incorrect language and full translation (Incorrect-Full), and (4) incorrect language and partial translation (Incorrect-Partial).

Four versions of a mock up of the B2C Thai online store were developed to correspond to the four conditions of the experiment. All versions of the website had identical visual design; only the textual content was different according to the experimental condition characteristics.

\subsection{Survey}

The participants were randomly assigned to one of the four experimental conditions, following a between-subjects design. They viewed the version of the mock up website corresponding to the condition and answered a questionnaire about their perception. The questionnaire included items adapted from previous studies: trust [5], ease of use [8], and ease of communication [12] [ 17]. The questionnaire also included items measuring self-perceived English language ability and interest in cross-border electronic commerce. Items were measured on a five-point Likert scale ranging from "strongly disagree" to "strongly agree". All items were translated to Japanese language by a native Japanese speaker and reviewed by a second native Japanese speaker.

\section{Results and Discussion}

\subsection{Sample}

After eliminating outliers and cases with suspicious response patterns, the total sample was 1919 respondents. The characteristics of the sample are summarized in Table 1. No statistically significant differences were found in the mean or distribution of age, sex or online shopping frequency between the experimental condition groups, indicating a successful random assignation.

Skewness indices (SI) and kurtosis indices (KI) were within the limits of SI $<3.0$ and $\mathrm{KI}<10$ [15] for all items, indicating that there were no deviations from normality. The Mahalanobis distance measure (D2) was used to identify multivariate outliers. These were eliminated, leaving 1826 valid cases. There were no missing data. Data validation was performed using SPSS v18 and Amos v18.

Table. 1. Sample summary

\begin{tabular}{|c|l|c|}
\hline Sample Size & & 1919 \\
\hline Age mean (sd) & & $45.3(15.0)$ \\
\hline Sex (\%) & Male & 51.1 \\
\hline & Female & 48.9 \\
\hline EC Frequency (\%) & None in the past year & 7.3 \\
\hline & Once a year & 4.2 \\
\hline & Twice a year & 7.9 \\
\hline & 2,3 times in 6 months & 20.1 \\
\hline
\end{tabular}


Vanessa Bracamonte Lesma \& Hitoshi Okada / Vol. 3, No. 3, December 2020, pp. 121-127

\begin{tabular}{|l|l|c|}
\hline & Once a month & 24.3 \\
\hline & 2,3 times a month & 25.1 \\
\hline & Once a week & 8.4 \\
\hline & 2,3 times a week & 2.2 \\
\hline & 4 or more times a week & 0.5 \\
\hline
\end{tabular}

\subsection{Identify the Headings}

We conducted confirmatory factor analysis (CFA) with a maximum likelihood estimation, to validate the model measurement structure. The self-perceived English ability control factor was included in the analysis. Amos v18 was used to conduct the CFA. Good model fit was determined with the following criteria: the root mean square error of approximation (RMSEA) should be lower than 0.06 ( $\mathrm{p}>0.05$ ), the standardized root mean square residual (SRMR) should be lower than 0.08 , and the comparative fit index (CFI) and the Tucker-Lewis index (TLI) should be higher than 0.95 [2]. Because of the large sample size, a normed chi-square ( $\left.\chi^{2} / \mathrm{df}\right)$ between 3.0 and 5.0 was considered acceptable [11] [20].

The initial model did not return a good model fit. An inspection of the factor loadings and modification indices revealed the sources of strain in the model. An item from the ease of use factor was removed and residual covariances were added. The re-specified model showed good fit: $\chi^{2}(53)=233.67(\mathrm{p}=0.0), \chi^{2} / \mathrm{df}=4.41$, RMSEA $=0.04(\mathrm{p}=$ $0.97), \mathrm{SRMR}=0.02, \mathrm{CFI}=0.99, \mathrm{TLI}=0.98$. All standardized factor loadings were above 0.7 , the values are shown in Table 2.

In order to verify construct reliability, Cronbach's alpha and composite reliability values were calculated for each factor. All values were above 0.7, indicating good construct reliability (Table 2). To verify convergent validity, the average variance extracted (AVE) of the factor was calculated. All values were above 0.5 , indicating good convergent validity (Table 2). Finally, in order to verify discriminant validity, the square root of the AVE of each factor was compared to the absolute value of the correlations with all other factors [10]. The square root of the AVE was higher for all factors, indicating good discriminant validity (Table 3 ).

Table. 2. Measurement mode

\begin{tabular}{|l|c|c|c|c|c|}
\hline Construct & Item & Std. Factor Loading & Cronbach's $\alpha$ & CR & AVE \\
\hline Trust & T1 & 0.85 & 0.89 & 0.90 & 0.75 \\
\hline & T2 & 0.86 & & & \\
\hline Ease of use & T3 & 0.88 & & & \\
\hline & U1 & 0.79 & 0.91 & 0.90 & 0.65 \\
\hline & U2 & 0.74 & & & \\
\hline & U3 & 0.84 & & & \\
\hline & U4 & 0.83 & & & \\
\hline Ease of Communication & C1 & 0.83 & & & \\
\hline & C2 & 0.84 & 0.86 & 0.87 & 0.69 \\
\hline
\end{tabular}


Vanessa Bracamonte Lesma \& Hitoshi Okada / Vol. 3, No. 3, December 2020, pp. 121-127

\begin{tabular}{|l|c|c|c|c|c|}
\hline & C3 & 0.83 & & & \\
\hline English Ability & E1 & 0.89 & 0.89 & 0.89 & 0.80 \\
\hline & E2 & 0.91 & & & \\
\hline
\end{tabular}

Table. 3. Discriminant validity

\begin{tabular}{|l|c|c|c|c|}
\hline & Trust & Ease of use & Ease of communication & English ability \\
\hline Trust & 0.86 & & & \\
\hline Ease of use & 0.74 & 0.80 & & \\
\hline $\begin{array}{l}\text { Ease of } \\
\text { communication }\end{array}$ & 0.81 & 0.79 & 0.83 & \\
\hline English ability & 0.11 & 0.18 & 0.21 & 0.90 \\
\hline
\end{tabular}

\subsection{Figures and Tables}

We tested the proposed model by conducting structural equation modeling (SEM) analysis with a maximum likelihood function, using Amos v18. Three dummy variables were created to represent the four experimental conditions in the structural model [18]. The correct language and full translation condition was used as the reference. The self-perceived English ability factor and the cross-border electronic commerce interest and frequency of online shopping variables were included in the model as controls. The initial structural model, specified according to the hypotheses of the study, showed a good fit: $\chi^{2}(98)=311.70(\mathrm{p}=0.0), \chi^{2} / \mathrm{df}=3.18$, RMSEA $=0.04(\mathrm{p}=1.0)$, SRMR $=0.02$, CFI $=0.99$, TLI $=0.98$. The results of the SEM analysis are detailed in Table 3 . All the hypotheses of the study were confirmed, except for H3. Therefore, we conducted mediation analysis to determine whether there was an indirect effect of the dummy variables on trust. In order to do this we ran a bootstrap of the model with 2000 bootstrap samples; the significance of the effects was calculated using $95 \%$ bias-corrected bootstrap confidence intervals [19]. The results showed that there were significant indirect effects on trust for all conditions: Incorrect-Full: $\beta=-0.11, \mathrm{p}<0.01$; Correct-Partial: $\beta=-0.13, \mathrm{p}<0.01$; Incorrect-Partial: $\beta=-0.16, \mathrm{p}<0.01$.

Table. 4. Structural model results

\begin{tabular}{|c|c|c|c|c|}
\hline Hypothesis & $\begin{array}{c}\text { Path } \\
\text { coefficient }\end{array}$ & $\begin{array}{l}\text { Std } \\
\text { error }\end{array}$ & $\beta$ & $\mathrm{p}$ \\
\hline $\begin{array}{l}\text { H1a: Incorrect-Full (dummy) -> Ease of } \\
\text { communication }\end{array}$ & -0.17 & 0.05 & -0.102 & $<0.001$ \\
\hline $\begin{array}{l}\text { H1b: Correct-Partial (dummy) -> Ease of } \\
\text { communication }\end{array}$ & -0.22 & 0.05 & -0.13 & $<0.001$ \\
\hline $\begin{array}{l}\text { H1c: Incorrect-Partial (dummy) -> Ease of } \\
\text { communication }\end{array}$ & -0.26 & 0.05 & -0.154 & $<0.001$ \\
\hline H2a: JP-Incorrect (dummy) $>>$ Trust & -0.016 & 0.031 & -0.01 & 0.616 \\
\hline H2b: EN-Correct (dummy) -> Trust & 0.033 & 0.031 & 0.021 & 0.289 \\
\hline H2c: EN-Incorrect (dummy) -> Trust & 0.058 & 0.031 & 0.037 & 0.064 \\
\hline H3a: JP-Incorrect (dummy) -> Ease of use & -0.211 & 0.036 & -0.126 & $<0.001$ \\
\hline H3b: EN-Correct (dummy) -> Ease of use & -0.197 & 0.036 & -0.117 & $<0.001$ \\
\hline $\begin{array}{l}\text { H3c: EN-Incorrect (dummy) -> Ease of } \\
\text { use }\end{array}$ & -0.225 & 0.036 & -0.133 & $<0.001$ \\
\hline H4: Ease of communication $->$ Trust & 0.587 & 0.041 & 0.745 & $<0.001$ \\
\hline H5: Ease of communication $->$ Ease of use & 0.758 & 0.03 & 0.62 & $<0.001$ \\
\hline H6: Ease of use $->$ Trust & 0.227 & 0.035 & 0.244 & $<0.001$ \\
\hline
\end{tabular}




\section{Discussion}

The main result of the study was the confirmation of the hypotheses that errors in the textual content of a foreign online store have a negative impact on perceived ease of communication and perceived ease of use. Compared to the website corresponding to the experimental condition of correct language and full translation, the websites for the conditions that included at least some type of textual error were perceived as less easy to communicate with and use. These results are in line with previous research [7], as these are factors that indicate quality in the website [1]. In addition, it is interesting to note that the difference between the standardized path coefficients for the dummy variables of the error conditions was very small. This suggests that the presence of one type of textual error was enough to have a negative impact on consumers' perception, regardless of whether the other component of the textual content of the website was correct or not.

In addition, the analysis confirmed the effect of ease of use on trust, in line with Gefen et al. [8], and the effect of ease of communication on ease of use and trust. The results also show that the standardized direct effect of ease of communication on trust was higher than the effect of ease of use. This indicates that the challenges of communication with the vendor may be more salient for consumers because of the cross-border context of the experiment.

The only hypothesis not confirmed by the results was the hypothesis that a website with correct language and full translation would directly result in higher trust compared with one with errors. In this case, none of the path coefficients of the dummy variables for the error conditions were significant. However, the mediation analysis showed that there was a significant negative indirect effect, and therefore a full mediation by the other factors in the model.

There are some limitations to this study. First, we used a mock up foreign online store instead of a real one, which limits the realism of the experiment. However, this is allowed for the flexible manipulation of the textual content and at the same time avoided any brand reputation effects. Second, the responses obtained were limited to the Japanese people who could be reached through the invitation to participate in the experiment extended by the online survey company. This limits the generalization of the results on the Japanese population.

\section{Discussion}

This study investigated the effect of textual errors on consumer perception towards a foreign online store. We considered two type of errors: incorrect language use and partial translation. Four different experimental conditions were tested: three conditions of textual errors and a reference condition of no errors. The results obtained showed that the presence of textual errors of any type had a negative effect on the perception of ease of communication, ease of use and trust in the foreign online store.

The implication of the findings of this study is that international vendors should strive to carry out quality assurance of the textual content in their website in a comprehensive manner. Even though translation is a costly process, vendors should take into consideration the disadvantages of a low quality or partial translation in relation to their particular target international audience.

Future research in this area should consider analyzing the model in different variations of the foreign online store country and the country of the respondents, to examine cross-country differences.

\section{References}

[1] S. Barnes and R. Vidgen, An integrative approach to the assessment of e-commerce quality, Journal of Electronic Commerce Research, 3 (3), 114-127, 2002.

[2] T. A. Brown, Confirmatory Factor Analysis for Applied Research. 2006, 483.

[3] Consumer Affairs Agency of Japan, 越境取引に関する調查の概要について Ekkyō torihiki ni kansuru chōsa no gaiyō ni tsuite, 2011.

[4] D. Cyr, M. Head, and H. Larios, Color appeal in website design within and across cultures: A multi-method evaluation, International journal of human-computer studies, 2010.

[5] D. Cyr, M. Head, and H. Larios, Exploring human images in website design: a multi-method approach, MISQuarterly, 33 (3), 1-32, 2009. 
Vanessa Bracamonte Lesma \& Hitoshi Okada / Vol. 3, No. 3, December 2020, pp. 121-127

[6] F. Davis, Perceived usefulness, perceived ease of use, and user acceptance of information technology, MIS quarterly, 13 (3), 319-340, 1989.

[7] A. Everard and D. F. Galletta, How presentation flaws affect perceived site quality, trust, and intention to purchase from an online store, Journal of Management Information Systems, 22 (3), 56-95, Jan. 2006.

[8] D. Gefen, E. Karahanna, and D. W. Straub, Trust and TAM in online shopping: an integrated model, MIS quarterly, 27 (1), 51-90, 2003.

[9] D. Gefen, E-commerce: the role of familiarity and trust, Omega, 28 (6), 725-737, Dec. 2000.

[10]D. Gefen, D. W. Straub, and M.-C. Boudreau, Structural Equation Modeling and Regression: Guidelines for Research Practice, Communications of AIS, 4 (7), 2000.

[11] D. Hooper, J. Coughlan, and M. Mullen, Structural equation modeling: guidelines for determining model fit, The Electronic Journal of Business Research Methods, 6 (1), 53-60, 2008.

[12] M. Jun, Z. Yang, and D. Kim, Customers' perceptions of online retailing service quality and their satisfaction, International Journal of Quality \& Reliability Management, 21 (8), 817-840, 2004.

[13]F. P. Karimov, M. Brengman, and L. Van Hove, The effect of website design dimensions on initial trust: a synthesis of the empirical literature, Journal of Electronic Commerce Research, 12 (4), 272-301, 2011.

[14] W. King and J. He, A meta-analysis of the technology acceptance model, Information \& Management, 43 (6), 740-755, Sep. 2006.

[15] R. B. Kline, Principles and practice of structural equation modeling, 156. 2011, 427.

[16] M. Koufaris, The development of initial trust in an online company by new customers, Information \& Management, 41 (3), 377-397, Jan. 2004

[17]E. T. Loiacono, R. T. Watson, and D. L. Goodhue, WebQual TM: A Measure of web site quality, Marketing educators' conference: Marketing theory and applications, 13, 432-438, 2002.

[18]R. C. MacCallum and J. T. Austin, Applications of structural equation modeling in psychological research., Annual review of psychology, 51, 201-226, 2000.

[19]P. E. Shrout and N. Bolger, Mediation in experimental and nonexperimental studies: new procedures and recommendations. Psychological methods, 7 (4), 422-445, 2002.

[20] S. Taylor and P. Todd, Understanding information technology usage: a test of competing models, Information systems research, 6 (2), 144-176, 1995.

[21] V. Venkatesh, Determinants of perceived ease of use: Integrating control, intrinsic motivation, and emotion into the Technology Acceptance Model, Information System Research, 11, 342-365, 2000.

[22] Y. D. Wang and H. H. Emurian, An overview of online trust: Concepts, elements, and implications, Computers in Human Behavior, 21 (1), 105-125, Jan. 2005. 